\title{
Engajamento desterrado: a relação de Vilém Flusser com o Brasil
}

\section{Rafael Alonso}

Doutor; Universidade Federal de Santa Catarina, SC, Brasil

rafamalonso@gmail.com

\section{Resumo}

Vilém Flusser é um pensador desenraizado. Judeu e praguense, tem a família assassinada pelos nazistas. Após um ano na Inglaterra, chega ao Brasil em 1940, onde viveria por pouco mais de três décadas. Filósofo multilíngue, faz da autotradução o seu pressuposto de pensamento, postulando que tantas são as realidades quantas forem as línguas articuláveis. Retorna à Europa em 1972 e, a partir de então, leva a vida entre palestras e conferências, sem se filiar formalmente a nenhuma instituição acadêmica. Apesar de sua biografia e filosofia desterradas, o conceito de engajamento não deixou de ser central em sua obra, sobretudo pelo tempo em que viveu no Brasil. É no Brasil que a veiculação afetiva e política a um lugar atravessa o pensamento deste filósofo apátrida, sentimento que o acompanha até o final da vida. A proposta deste artigo, a partir da leitura atenta da correspondência inédita com alguns de seus principais interlocutores, é discutir o engajamento brasileiro de Flusser. A premissa é que Flusser forjou um modelo imaginativo, ainda que sem a pretensão de formular uma "filosofia brasileira", que pode servir de chave crítica para o entendimento do Brasil contemporâneo. As dúvidas sobre as formas de engajamento no Brasil, que atravessaram a vida de Flusser, especialmente nos anos 1970, estão colocadas à mesa novamente.

\section{Palavras-chave}

Vilém Flusser. Brasil. Europa. Engajamento. Correspondências.

\section{Introdução}

A realidade brasileira convoca ao engajamento, espontânea ou forçadamente. Ela exige que se marque posições, que se demarque espaços. Ela demanda defesa, isolada ou coletiva. Pensar no Brasil é tomar posição, e mesmo quem não deseja tomar posição 
precisará justificar a escolha pela não escolha. Ainda mais em tempos em que, para lembrar Georges Didi-Huberman (2008), tomar posição transforma-se em sinônimo de tomar partido. Em momento de acirramento político, o que, por aqui, recebeu o nome de "polarização", a simples assunção de entendimentos racionais ou a mera corroboração de pressupostos científicos pode implicar em identificação partidária à direita ou à esquerda, progressista ou conservadora.

É a própria política que está em xeque. 0 sensível passa a ser compartilhado nas redes sociais. Não existe democracia sem república, sem coisa pública, mas a coisa pública e o espaço público desaparecem do horizonte. 0 espaço público é o espaço das trocas. 0 filósofo Vilém Flusser (1920-1990) se dá conta dessas contradições em suas últimas conferências, pronunciadas na Alemanha, pouco antes de morrer, em 1990: "Meu empenho para publicar fica enfraquecido quando dou uma palestra aqui em Bochum em vez de escrever um fax em casa. Captem o impacto dessa revolução; a república não é só desnecessária, mas incômoda" (FLUSSER, 2014, p. 91). Ele questiona ironicamente os seus ouvintes acerca da diferença que, hoje em dia, poderíamos estabelecer entre participar de um congresso acadêmico ou permanecer em casa para escrever e publicar um artigo em uma revista.

Para Flusser, política é sinônimo de publicação. Publicar não para pontuar ou enriquecer - currículos ou contas bancárias. Publicar não porque "tenho que publicar", mas porque "não consigo não publicar". Publicar para atender a um desejo, a um impulso incontido, a um anseio de comunicar. Publicar é dar forma a um informe, é in-formar, é oferecer ao mundo aquilo que, se trancafiado no privado, acabará por consumir o guardião da cela. A publicação responde a uma angústia privada, mas necessita da escuta. A arte parte do privado e é recebida no privado, mas não pode abdicar do público - do espaço e das pessoas.

A questão está desenhada com as cores do contemporâneo, mas Flusser não deixou de se deparar com ela - e de enfrentá-la - nas décadas de 1960 e 1970. Grosso modo, isso que se define como engajamento, tema central deste ensaio, é decisivo para Flusser, como consta em sua autobiografia filosófica:

[...] todos os temas têm sido e continuarão a ser variações de um único: o problema do engajamento a partir de uma situação sem fundamento. Isto é assim porque a própria vida da gente (vida-ensaio) é variação desse único tema, o qual pode aforisticamente ser formulado como: busca de fé na desgraça (FLUSSER, 2007, p. 81). 
Engajar-se não é, apenas, engajar-se em causas. Engajar-se, em sentido amplo, é pendurar-se em algum galho frágil do mundo para não cair no abismo. Flusser descobre muito cedo, quando é obrigado a fugir de Praga, em 1939, deixando para trás as ruínas da sua cidade e as cinzas dos seus outros, que a vida-ensaio, vida-teste ou vida-tentativa não tem fundamento. A vida no Brasil, que durou de 1940 a 1972, é absurda e os engajamentos que se seguiram na realidade brasileira não diminuíram a sua condição de absurdidade, como se tentará exemplificar nos parágrafos seguintes.

Flusser naturaliza-se brasileiro na década de 1950 e afirma que "demorou até o ano de 1972 para que eu me decidisse, de maneira dolorosa, a desistir de meu engajamento no Brasil e fosse morar na Provença, esse anti-Brasil” (FLUSSER, 2007, p. 229). A decepção de Flusser com o Brasil, que depois se estenderá à realidade concreta do país (social, econômica e cultural) começa pela descoberta de que a ideia de pátria é a "sacralização do banal" (FLUSSER, 2007, p. 230). Para manter a sua liberdade apátrida, ele lembra que é necessário recusar essa mistificação dos hábitos. Isso não implica em recusar as ligações feitas no Brasil, pois se sentia responsável por elas, mas abrir-se a outras ligações, às quais poderia incorporar a experiência brasileira. "Não é que o Brasil não seja a minha pátria, pois 'pátria', para mim, são os homens pelos quais eu tenho responsabilidade" (FLUSSER, 2007, p. 230). É possível um engajamento desterrado? É sobre essa questão que o presente artigo reflete nas páginas seguintes. A hipótese é que o desencanto de Flusser com o Brasil, que nunca implicou em desistência ou no abandono de seus interlocutores, deixa pistas para a construção de um pensamento crítico sobre o país ainda hoje.

\section{0 desencanto com o Brasil e o retorno à Europa}

Flusser chega ao Brasil em 1940. 0 clima existencial dos anos seguintes - e do resto da vida - seria de bodenlos ("sem fundamento", do alemão, e também título de sua autobiografia filosófica), de completo desenraizamento, arrancado que foi, brutalmente, da proximidade de sua família, de sua cidade e de sua língua. Ao mesmo tempo, a falta de fundamento, como ele admite, concede-lhe liberdade vertiginosa, pois poderia engajar-se em quantas fossem as línguas e as culturas, livre do fascismo do sangue e dos conceitos essenciais, tais como o de povo, língua materna, pátria etc. Toda a teoria flusseriana da língua e da tradução está fundada, ou melhor, a-fundada, nesta absoluta ausência de solo firme. 
Flusser parte para o Brasil com os olhos voltados para a ruína - a Praga em destroços - e desembarca em um país onde a guerra parecia ser coisa de outro mundo, tamanha a distância alienante que os brasileiros mantinham da situação. "Tudo o que estava acontecendo no Brasil se apresentava à gente como um fazer-de-conta deliberado. As pessoas que cercavam a gente suspendiam não apenas o saber da bomba, mas também o saber do poder decisório que exerciam os Estados Unidos sobre o Brasil" (FLUSSER, 2007, p. 56).

A primeira porta que se abre é a do Suplemento Literário d'O Estado de São Paulo, através de Décio de Almeida Prado. Uma porta simbólica, pois conforme se lê em Bodenlos, a colaboração de Flusser neste periódico resume os conflitos enfrentados por ele durante todo o período em que se engaja na cultura brasileira. Ele confessa que a "penetração" no caderno cultural do Estadão foi tarefa fácil, mas admite que tem de lidar com uma "panela", como ele chama os colaboradores do jornal paulistano, com a qual não concorda em praticamente nada. Além disso, ele ainda considera superficiais as respostas que obtém de seus ensaios e distantes da envergadura e do esforço de pensamento que neles imprime. Por fim, Flusser lamenta que a colaboração não implique em poder decisório sobre o jornal, mas apenas em responsabilidade individual, o que aumenta seu isolamento: "Em suma: o sabor da derrota invadia desde já as primeiras vitórias fáceis. E foi em tal clima que se iniciou o engajamento todo" (FLUSSER, 2007, p. 83).

No relato autobiográfico Em busca de significado (FLUSSER, 1976), Flusser confessa que não tinha se encontrado no Brasil, bem como não tinha encontrado o Brasil em si. Se, no começo, empolga-se com a poesia concreta e a bossa nova, o retorno à Europa é cercado de melancolia e desencantamento. A volta não é decisão simples, pois dentro das problemáticas conceituais e existenciais que se apresentam, Flusser precisa decidir se seria mais produtivo seguir à margem ou encaminhar-se ao centro.

0 caso brasileiro, quando resolve retornar à Europa, no início dos anos 1970, tem uma peculiaridade. 0 país vive um regime de exceção. A leitura de seus textos e correspondências dá a entender que a ditadura era a virtualidade mais provável do programa brasileiro. 0 seu principal interlocutor no assunto é o jurista conservador Miguel Reale (1910-2006). Em meados do século XX, Flusser visualiza dois caminhos para o Brasil consolidar-se enquanto "nação": populismo e tecnocracia. Segundo ele, o desafio é lidar com uma sociedade estratificada em três camadas: uma grande massa seminômade - miserável, doente e faminta -, um proletariado urbano e uma burguesia formada por imigrantes e descendentes 
de "conquistadores". Neste sentido, Flusser indaga: se a missão da burguesia é forjar o país, a quem deve se dirigir, aos trabalhadores das cidades, para conscientizá-los, ou à multidão passiva e inculta? Em termos contemporâneos, a questão implicaria pensar em formas de mobilização de, por um lado, uma grande massa pobre e miserável que, aparentemente, passa ao largo das decisões políticas e que pode conferir seu voto a governos que tendem a liquidar seus escassos direitos, e, por outro, convencer a uma outra parcela da população, igualmente numerosa, de que seus esforços de trabalho ou de empreendedorismo não lhes permitem ascender socialmente e tomar parte entre as classes privilegiadas.

Essas são as perguntas que Flusser se faz. Para ele, as duas opções são impossíveis, pois mobilizar os cidadãos passa por politizá-los e abordar a massa passa por interferir na economia. Ele resume a encruzilhada em sua autobiografia:

Havia, portanto, duas opções: engajar-se a favor da liberdade ou na luta contra a fome e a doença. É muito difícil colocar claramente a si mesmo uma escolha impossível como essa. Eu tentei, mas fracassei. A tendência "populista", que veio com o comando de Vargas e cuja última influência foi o presidente que faleceu antes de assumir o poder, acreditava escapar dessa escolha impossível: em primeiro lugar, era necessário mobilizar politicamente os trabalhadores para, em seguida, poder puxar a massa. Isso conduziu a uma demagogia fascistóide e a uma vulgarização de todos os empreendimentos culturais. A segunda tendência, a "tecnocrática", pegou o dilema pelos chifres. Tratava-se, em princípio, de acabar com a miséria, e para poder fazê-lo era preciso planejar de maneira centralizada. Um tal planejamento pressupõe ditadura e impedimentos "provisórios" para qualquer perturbação social, política e cultural do plano. Essa tendência "tecnocrática" está incorporada no exército - um grupo composto de cidadãos. Depois de 1964, ficou claro para mim que a vitória da tecnocracia sobre o "populismo" era o único caminho para fazer do Brasil finalmente uma pátria. E também pude imaginar o aspecto dessa pátria: um aparelho gigantesco e progressivo que, em termos de inépcia, patriotismo e preconceitos patrióticos, não ficaria atrás de nenhuma pátria europeia (FLUSSER, 2007, p. 229).

Antes de desistir do engajamento brasileiro - e antes de desistir de fazer do Brasil a sua pátria - Flusser tenta, de diversas formas, ajustar-se à realidade brasileira, mas confessa, em carta a Miguel Reale de $1^{\text {o }}$ de outubro de 1971, que nenhuma delas surtiu efeito satisfatório.

Da Universidade de São Paulo (USP) USP, conta que se considerava em "posição humilhante e mal paga", e que apenas os alunos salvavam o ambiente, tomado pela "tecnicalidade". Flusser não engole o fato de a editora da universidade ter recusado a 
publicação de um de seus livros por alegar falta de dinheiro. Da faculdade Armando Penteado, a FAAP, admite que contava com uma "qualidade de receptores frustrante" e que era ambiente tomado de "alienação e futilidade". Do Instituto Brasileiro de Filosofia (IBF), explica que lhe faltou capacidade organizadora para que suas atividades tivessem maior sucesso. Das conferências e cursos particulares, dos quais admitidamente retirava o seu sustento, afirma que teve de interromper as atividades sob ameaça de "degenerar em prostituição degradante". Da colaboração no Estadão, sobre a qual já se falou, lamentava o excesso de respostas negativas e a ausência de apoio moral e intelectual. Das demais publicações - revistas e periódicos em geral -, diz que carecia de feedback e que ignorava seus efeitos. De tentativas mais ousadas, como programas de televisão, avalia que foi censurado na TV Cultura e pego na malha do comercialismo na TV Tupi.

As suas possibilidades no Brasil parecem esgotadas. Ele, de fato, investe em várias frentes, mas em nenhuma delas alcança a resposta esperada. Ao mesmo tempo, o interesse por sua obra na Europa começa a crescer, e Flusser também vê no retorno a chance de criar outra forma de engajamento, ou mesmo de abrir mão de todo engajamento:

\begin{abstract}
Mas principalmente há isto: lá não me engajo. Os europeus que se danem, desde que me paguem. Posso fazer lá o que me compete fazer por vocação, sem respeito pela sociedade. A saber, no momento: posso isolar-me para escrever uma análise da minha circunstância imediata, inspirada pela fenomenologia, a chamar-se, talvez, ('coisas que me cercam'), título aliás de uma coletânea de artigos meus a serem publicados pela Comissão Estadual de Cultura, cujo manuscrito, aceito e pago com cem cruzeiros, está tramitando atualmente pelos labirintos kafkianos desse aparelho administrativo. De forma que talvez poderia ser na Europa "homem famoso", mas quase certamente poderia trabalhar sem estar perturbado por engajamento (FLUSSER, 1971) ${ }^{1}$.
\end{abstract}

Em linhas gerais, Flusser confia que o terreno na Europa já está preparado para receber e criticar o seu pensamento. Ele reputa seus interlocutores como mais habilitados e as respostas que recebe como mais efetivas. A vida é mais barata, e ele melhor remunerado. A publicação de seus trabalhos é mais frequente e os processos burocráticos fluem com naturalidade. 0 ressentimento com a situação brasileira fica evidente em carta a Alan Meyer, um ex-aluno, de 31 de agosto de 1973:

\footnotetext{
1 Esta, e todas as demais cartas que serão citadas, não estão publicadas em livro. 0 autor teve acesso ao material durante pesquisa no Vilém Flusser Archive, na Universidade das Artes, em Berlim, entre maio e outubro de 2017.
} 
Explico sem falsa modéstia: Meu pensamento nunca foi adequadamente distribuído no Brasil, porque nunca me deram a importância que me dão na Europa. Agora sei que sou "válido", coisa que a circunstância brasileira encobriu para mim por razões que não vem ao caso. Depois de 30 anos de sistemática diminuição pelo ambiente assumo-me o que sou: pensador original e "relevante" para alguns dos problemas mais importantes da atualidade. Pois o Brasil continua sendo meu público, e a editora Documentário de Margulies está disposta a abrir, finalmente, tal público para mim. [...] Posso romper daqui finalmente o ostracismo ao qual a circunstância me condenou durante tanto tempo na forma de marginalização, diminuição, crítica impertinente e academismo. Não tome isso por megalomania: sei agora objetivamente que os que me criticaram, leram ou não leram etc. simplesmente não perceberam o meu trabalho. Sei isto objetivamente, no sentido de poder comparar a atitude brasileira com a européia com relação aos meus escritos. Você deve compreender a angústia que isto me dá: sei que posso ser elemento decisivo na decolagem cultural brasileira, mas os brasileiros, inclusive você, o ignoram (FLUSSER, 1973a).

Em carta a Dora Ferreira da Silva, de 29 de dezembro de 1975, já devidamente instalado na Europa, Flusser compartilha, a pedido da amiga, as primeiras impressões do retorno. Ele avalia que a rotina em São Paulo havia se tornado "irracional". Podia-se fazer muito pouco, e do pouco que se fazia colhia-se resultados irrisórios comparados aos esforços e gastos despejados. Era "banal" o que se aprendia e se absorvia nas últimas tentativas de engajamento. Flusser confessa que prorrogou a volta em razão do apego aos amigos e ao que chama de "coisas brasileiras", além da paixão sempre admitida dos filhos pelo país, mas que chegara o momento decisivo a partir do qual "um dos pratos da balança superou definitivamente o outro". Flusser descreve a Dora o andamento atual da vida em solo europeu e elenca as vantagens que retira de sua nova forma de estar-no-mundo:

[...] trabalho mais concentradamente, publico em veículos mais condizentes ao meu pensamento, dou aulas para pessoas que podem aproveitar melhor as dúvidas que irradio, participo ativa - e passivamente - de experiências mais variadas, aprendo muito, tenho vida mais intensa e de menor rotina, estou cercado de cultura e natureza mais estimulante, sou mais livre em muitos sentidos (inclusive no da deslocação geográfica), e estou em convivência mais intensa e satisfatória com a Edith. E quanto ao meu engajamento: deslocou-se do nível social (publicar e dar aula para alguém) para um nível epistemológico (publicar e dar aula sobre algo) (FLUSSER, 1975).

Ele reafirma que o Brasil é o seu lugar de engajamento, a sua "realidade" e onde gostaria de mudar as coisas, mas conclui que, no longo prazo, seu engajamento em todas as instituições e mídias foi decepcionante e que sua vida caíra em comodidade não produtiva. É 
neste ponto que escolhe a vida na Europa, economicamente estabilizada e sem a necessidade do que chama de engajamento social. É como se, na Europa, o clima intelectual e os espaços em que poderia circular e publicar já estivessem consolidados e abertos a receber o seu pensamento, enquanto que, no Brasil, Flusser constantemente se queixa de não ser compreendido ou de esbarrar nos labirintos da burocracia brasileira - tanto das editoras, para publicar seus livros, quanto das universidades, já que tenta, sem sucesso, estabelecer parcerias de colaboração entre a FAAP e instituições estrangeiras. Em síntese, Flusser acredita que, na Europa, não precisaria fazer grandes esforços para manifestar a relevância e a atualidade do seu pensamento.

Na linha de Flusser, é possível, no contexto brasileiro, acreditar em engajamento epistemológico? Não tem razão Dora, quando pede ao amigo, em carta de 10 de junho 1973: "Flusser: volte. As coisas só vão acontecer na América do Sul. A Europa é para visitar museus e ver a beleza das paisagens e das cidades, que também são paisagens" (SILVA, 1973a). Já em carta de 5 de maio de 1973, Dora brinca com o amigo e sugere a fundação hipotética em "Campos de Jordão de um novo mundo, em torno de um novo centro. Ritualisticamente" (SILVA, 1973b). É possível fundar qualquer coisa no Brasil ou o melhor é deixar que ele afunde? É possível um caminho do meio que conjugue engajamento social e engajamento epistemológico?

Flusser, antes de partir, tentou uma última cartada: reorganizar a Bienal de Arte de São Paulo, mas também sem sucesso, como admite em carta a Edmar de Almeida, de 5 de dezembro de 1972: "Desisti, com a Bienal, também de toda Jerusalém terrestre” (FLUSSER, 1972). Ele abandona, com a Bienal, toda possibilidade de aplicação de um modelo teórico a uma realidade social - Flusser tentou transformou a Bienal no que chamou de "laboratório criativo", mas, principalmente por discordâncias com Francisco Matarazzo, por quem chegou a ser financiado para planejar o evento, abandonou a ideia. Será por isso que, a partir da década de 1980, Flusser insista recorrentemente que as imagens técnicas desprezam a realidade objetiva? Será por isso que, também neste período, desvie levemente o seu argumento e passe a admitir que pensar o mundo contemporâneo não era mais propor modelos, mas jogar estrategicamente com modelos? Flusser retorna à Europa e escreve a sua autobiografia, Bodenlos, um "monumento ao engajamento", segundo conta em carta a José Bueno, de 14 de dezembro de 1973: “Aqui [com Bodenlos] jaz um engajamento nascido em 1940, morto no campo de batalha em 1972, e à (sic)espera pela ressureição dos corpos". (FLUSSER, 1973b). 


\title{
30 desterrado e a imensidão
}

Como articular o Brasil? Como articular o abismo? Como articular os dois polos entre os quais oscila a realidade brasileira, o de Juscelino e Brasília, ou da "historização imanentista", e o de Riobaldo e a Transamazônica, ou da "existencialização transcendentizante" (FLUSSER, 2007, p. 59)? 0 chamamento da vastidão é a dimensão da realidade brasileira.

A imensidão brasileira convida e seduz. Ainda mais a um desterrado, plurilíngue e sedento, "esponja que pode chupar elementos de não importa que cultura (talvez seja este o verdadeiro significado do termo cosmopolitismo: capacidade de aproveitamento universal passivo e irresponsável)" (FLUSSER, 2007, p. 67). Não foi difícil a Flusser tomar lugar na intelectualidade nacional, ainda que pelas beiradas: "Fui cuspido, pela fúria dos acontecimentos, no Brasil - que é uma situação plástica, muito amorfa, faminta e sedenta em todos os sentidos, também no ôntico" (FLUSSER, 1976, p. 496) ou, segundo explica em carta a José Bueno, de 31 de agosto de 1987:

\begin{abstract}
Durante muito tempo nutri a esperança de ver surgir em tal paizcontinente(sic)cultura nova. Por isto me engajei nela ensinando, escrevendo, e mantendo série de diálogos altamente criativos. Finalmente, decepcionei-me. Não por razões econômicas, políticas e sociais, mas por compreender que não sou a pessoa indicada para tal engajamento. Meu interesse é por demais "abstrato" para ter justificativa em situação concretamente dolorosa. Achei pois mais honesto mudar para cá, aonde meu engajamento tem mais justificativa. No entanto: continuo tentando contribuir para o diálogo brasileiro, sobretudo publicando (FLUSSER, 1987a).
\end{abstract}

Flusser via no Brasil a possibilidade de propor um novo humanismo, um novo homem, um homo ludens, em conceito que empresta de Johan Huizinga e que toma as formas do jogo como constituintes das estruturas de organização sociais. Um conhecimento que fosse capaz de articular a imensidão brasileira sem historicizá-la - ou sem recair em pressuposto historicista, segundo os termos que Walter Benjamin emprega para criticar a ideia de uma história linear e que caminharia em sentido unívoco e evolutivo. Um pensamento progressista que não acreditasse no progresso, pois, para Flusser, era nítido que o progresso tecnológico e o avanço desenfreado do capitalismo não culminariam em sociedade dita desenvolvida, como já era possível constatar em seu tempo com os fracassos norte-americano e europeu. Não um projeto de Brasil, ou uma filosofia brasileira ou à 
brasileira, mas uma forma que tornasse o pensamento no Brasil possível, que permitisse pensar no Brasil, um modelo que não dependesse, mas que não ignorasse a realidade brasileira. No entanto, Flusser confidencia à amiga Maria Lilia Leão, em carta de 5 de maio de 1987, a dificuldade de pensar em circunstância brasileira: "Como você sabe: não gosto de imensidades. A medida é sintoma da humanidade, (anthropos metron panton), e 'est modus in rebus, sunt certi denique fines'. Por que o Brasil não deu certo? Por ser imenso. Conheço Buarque, mas Edith está lendo" (FLUSSER, 1987b).

Buarque é Sérgio Buarque de Holanda, com quem Flusser cruza nos seminários da Bienal de São Paulo, no começo dos anos 1970. O esforço de Buarque em procurar pelas raízes do Brasil é empenho histórico e sociológico, sem dúvida, e que se responde à falta de fundamento do Brasil de modo diferente a Flusser, admite, em termos semelhantes, que somos "desterrados em nossa terra" (HOLANDA, 1995, p. 31). O Brasil forma um "todo incoerente e amorfo", e não deixa de ser um mérito de Sérgio Buarque o de ter percebido que essa massa amorfa, que resiste a princípios racionalizadores de organização da vida, cede sem resistência à instauração de regimes autoritários. Mais do que isso: como uma sociedade amorfa apoiada em personalismo, como é a brasileira, tende a um "tipo de organização política artificialmente mantida por uma força exterior que, nos tempos modernos, encontrou uma das suas formas características nas ditaduras militares" (HOLANDA, 1995, p. 61).

Em carta a Miguel Reale, de 17 de junho de 1988, Flusser conta que preparava um texto para ser publicado em coletânea da editora Fischer Verlag, em colaboração com a Universidade Goethe, de Frankfurt, cujo tema seria "o intelectual e a cidade". Flusser estava imbuído de escrever sobre o intelectual de São Paulo. Para facilitar o argumento, ele divide a cidade em três camadas: casa particular, praça pública e templo, ou economia, política e filosofia. Ocorre que, dentro deste esquema, São Paulo não seria cidade, mas "conjunto de casas particulares sem praça pública nem templo". A cidade de São Paulo seria dominada pela economia, produção e consumo, sendo a despolitização e a desteorização resultado de aglomeração artificialmente criada (colônia), já que colonos não necessitam de praças e templos. Em São Paulo, portanto, as ideias seriam importadas e toda política recairia, necessariamente, em "politicagem (mimesis)": "E os intelectuais paulistanos formam arquipélago no qual cada ilha de solidão está desligada das demais ilhas, mas ligada subterraneamente aos jardins zoológicos europeus e norte-americanos. Isto é a tragédia e a glória dos intelectuais paulistanos" (FLUSSER, 1988). 
Em carta a José Bueno, de 1990, ele lamenta que, provavelmente, não voltaria mais ao Brasil. Reconhece que havia no país, há uma ou duas gerações, a esperança racional de que a sociedade brasileira se transformaria em alternativa para a Europa, já que aproveitara economicamente a fraqueza europeia no pós-guerra, culturalmente recebera imigração culta e socialmente estava formada por pessoas relativamente sem preconceitos e abertas ao mundo. No entanto, a esperança se revelou uma "fata-morgana tipo 'o petrólio é nosso', Brasília, Amazônia, petrodólares, Tancredo. Mas eu tinha participado de tal fata-morgana (por exemplo enquanto "embaixador extra-ordinário" do Itamarati na Europa e nos EEUU)" (FLUSSER, 1990d).

Edgardo Pereira Mendes, o Gazu, um ex-aluno de Flusser, afirma em correspondência de 23 de junho de 1988 que o intelectual brasileiro nasce clivado por esta situação herdada e passa quase toda a vida cindido entre uma solidariedade latino-americana ("solidariedade debaixo da ponte") e o fascínio pela "proa da nau do Ocidente que quer queiramos quer não, se chama Europa e sua variante recente a América do Norte" (MENDES, 1988). É o intelectual brasileiro, afinal de contas, um desterrado, um ilhado, um navegante à deriva, e que sonha em tomar lugar privilegiado na nau ocidental? É o intelectual brasileiro um marginal? Como forjar um pensamento original à margem e, ao mesmo tempo, fazer jus a uma herança cultural inescapável?

\section{A recusa da filosofia "tupiniquim"}

O que está em jogo, para Flusser, é a proposição de um pensamento que despreze conceitos totalizantes - sangue, terra, pátria - e que não recaia na ladainha da universalidade das ideias e do conhecimento. Como se comprometer com o Brasil sem fazer dele uma terra prometida? Pensar no caminho antropofágico é inescapável a esta altura. É sobre essa possibilidade que Flusser divaga com o mesmo Gazu, em carta de 15 de dezembro de 1978:

Sei vagamente que o motivo da antropofagia é o desejo de incorporar o outro, com suas qualidades supostamente superiores às próprias. Sei que segundo Freud a criança "introjeta" a mãe com a idade de 1 ano, que a "devora" junto com o leite, e que a mãe devorada passa a ser o núcleo do futuro eu da criança. Sei finalmente que o "devorar o deus", (enthusiasmos), do qual a hóstia da missa é um exemplo, é simultaneamente a humanização do divino e a divinização do homem. Há portanto, no conceito de antropofagia, algo que pode ser chamado de "essência da 
comunicação e da comunhão", coisa que o movimento antropofágico brasileiro dos anos 20 deve ter pressentido vagamente. (Não posso verificá-lo aqui por falta de documentação, e minha lembrança está ficando nebulosa quanto a esse movimento, embora tenha conhecido alguns dos seus participantes, inclusive o próprio Andrade). Se portanto o teu tema de interesse continuar a dizer respeito à comunicação, recomendo que te concentres sobre a antropofagia. Inclusive no sentido de "man eater", no qual certos tigres e certas mulheres são assim chamadas na literatura inglesa (FLUSSER, 1978).

A antropofagia não soa, aos ouvidos de Flusser, como uma estratégia cultural ou mesmo como um método de conhecimento. Ele encara a antropofagia como um princípio comunicativo, uma forma de diálogo natural e autêntico, com o meu outro, independentemente de onde provenha. Antropofágico, para Flusser, seria menos o gesto de incorporação das qualidades supostamente superiores do outro do que a abertura a uma troca comunicacional encarnada com o outro.

A posição de Flusser sobre o assunto pode ser mais bem avaliada em carta a Roberto Gomes, de 26 de setembro de 1980. Nessa correspondência, ele acusa Gomes de citá-lo levianamente e fora de contexto em Crítica da razão tupiniquim, de 1977. Nas três páginas que dedica a Flusser, Gomes questiona o postulado de que a filosofia não depende de espaço e tempo específicos e também critica, ironicamente, o fato de Flusser ter apontado que os expoentes da filosofia brasileira, à época, seriam Miguel Reale, Vicente Ferreira da Silva e Leônidas Hegenberg, pois na opinião de Gomes estas não eram figuras proeminentes do pensamento nacional. Gomes defende a urgência de se forjar um pensamento nacional, que estaria, sim, atado às circunstâncias nacionais, um pensamento tupiniquim que acompanharia as formulações antropofágicas de Oswald de Andrade.

A resposta de Flusser é clara: o intelectual brasileiro não deve se assumir tupiniquim, mas se assumir ocidental. Assumir-se é, antes de tudo, criticar a própria posição. Flusser rechaça o pensamento reativo, transgressor e marginal. 0 pensamento do intelectual brasileiro não assume seus pressupostos porque é o lado fraco da moeda, o lado passivo ou a metade sofredora da história, mas porque está informado pelos mesmos modelos que informam o pensamento europeu. É possível recusar a lógica ocidental de pensamento? Para Flusser, o absurdo do pensamento ocidental não é fazer poesia depois do campo, mas ter de assumir que não há outra forma de seguir adiante que não seja a de insistir em um modelo falido. 0 pensamento do "primeiro mundo" não deve ser recusado ou evitado, deve ser levado às últimas consequências: 
É preciso assumir-se, antes de querer alterar-se. Se o sr. se assume tupiniquim, se se identifica falsamente com o caboclo e o favelado, em vez de identificar-se, como é de seu dever intelectual e existencial, com o intelectual europeu, jamais poderá superar-se. A meu ver, longe de ter o sr. decifrado o mundo codificado atual, e seu aspecto brasileiro, o sr. caiu vítima da ideologia descolonizadora, como se o sr. não fosse colonizador, não colonizado. Antes do sr. não se assumir responsável, não apenas do salário mínimo de \$65, mas também por Auschwitz e da crise da ciência ocidental, o sr. jamais poderá querer tomar decisões quanto à sua atuação na cena brasileira. 0 que os aparelhos programam é precisamente esta atitude sua, assumida no seu livro. Preferem eles que os tupiniquim se chamem Roberto Gomes, em vez de se chamarem Benedito da Silva ou Minoki Akaoko (FLUSSER, 1980).

Flusser morre em acidente de carro a caminho de Praga. Ele era cego de um olho, e a esposa Edith, que dirigia, sobrevive. Flusser daria uma conferência na universidade em que seu pai havia sido reitor. 0 tema giraria em torno dos nacionalismos, mais especificamente sobre o perigo do retorno do fascismo em suas múltiplas roupagens. Depois de fugir do fascismo para não morrer, em 1940, Flusser morre a caminho de uma palestra em que alertaria os seus ouvintes sobre a iminente volta do fascismo.

\section{Conclusão}

Ler as correspondências de Flusser nas datas próximas à de sua morte é tarefa emocionalmente árdua. Flusser, claro, desconhecia o seu iminente e abrupto fim, mas no começo da década de 1990, tendo ultrapassado os 70 anos, ele analisa retroativamente o seu engajamento brasileiro. Em carta a Maria Lília, de 29 de janeiro de 1990, ele se diz tocado com o fato de a nova geração brasileira, ao lembrar-se dele, considerá-lo "pensador maldito e marginal": "Ora, é verdade que jamais fui absorvido pela cultura brasileira, mas é igualmente verdade que, embora seja 'reconhecido' aqui, continuo marginal (embora não maldito)" (FLUSSER, 1990b). Flusser, por certo, está longe de ser um pensador maldito, mas segue, ainda nos dias de hoje, ausente da enorme maioria das listas bibliográficas dos cursos de graduação e pós-graduação brasileiros, reflexo, talvez, do fato de nunca ter se ajustado ao pensamento sistemático e acadêmico.

Até o final da vida, ele não deixou de tentar construir pontes por sobre o abismo, de traduzir a história em pós-história, de engajar-se no Brasil ou de lançar pequenas bolhas de ar em terra submersa a fim de tornar a circunstância respirável, como no sonho que relata a 
Dora Ferreira da Silva, em carta de 29 de julho de 1990:

Esta noite sonhei com o Brasil como terra submersa em aquário, do qual surgem bolhas de ar, e tua carta era uma de tais bolhas. Simultaneamente estava consciente que meu passado (e o de Edith) estava incluído em tal terra submersa, que algumas das bolhas eram memórias minhas e que os mortos amigos continuavam vivos em tal submersão respirante. Acordei mal humorado (FLUSSER, 1990c).

Flusser volta à Europa, mas não deixa de lançar bolhas de ar pelo Atlântico. A sua busca não era pelas raízes, mas pelas entranhas. Ele nunca se assumiu tcheco, brasileiro, judeu, europeu, alemão, filósofo, mas também nunca deixou de reconhecer que todos esses modelos o informavam. 0 tom emotivo, quase dramático, das últimas cartas entre Flusser e Milton Vargas, que tinham por pano de fundo o retorno do primeiro a Praga, passava pela hesitação de Flusser em aproveitar a ocasião para retomar a cidadania e o passaporte tchecos, algo que Edith já havia feito. Na última carta de Milton, em 21 de novembro de 1990, uma semana antes da morte de Flusser, ele insiste para que o amigo recupere os seus direitos civis (VARGAS, 1990). Flusser não o fez, por falta de tempo ou porque não o faria de qualquer jeito, e até o fim da vida andou pelo mundo com o passaporte brasileiro.

O desfecho da trajetória de Flusser se dá entre cruzamentos apátridas. Sua preocupação não era, em idade madura, a de finalmente encontrar-se. Diferentemente disso, ele queria reconhecer-se: no Brasil, em Praga, nos amigos, nas imagens técnicas, no ser judeu. Conhecer, ou conhecer-se, não era identificar a substância pela qual estava formado, mas perceber as sombras pelas quais estava atravessado. Flusser, aos 70 anos, propunha colunas à Folha de São Paulo, relutava em recuperar a cidadania praguense, aventurava-se nos meios técnicos e planejava uma exposição em parceria com Jacques Derrida².

A originalidade de Flusser não está no fato de estar "entre", "sobre" ou "abaixo", mas de estar dentro, e quem está dentro pode simplesmente funcionar, mas pode, por outro lado, também deslocar. Não ocupar espaço, mas abrir espaço. Flusser, para além de ter articulado o Brasil e todos os temas que desenvolveu, oferece um modelo de pensamento que permite criticar a circunstância atual. Engajar-se no Brasil segue uma tarefa arriscada. A questão

\footnotetext{
2 A exposição se chamaria "The image of thinking" e também contaria com a colaboração de Dietrich Mahlow. Ela teria lugar em Nova York, Paris e Colônia. Essas informações constam em carta de Flusser a Ana Mae Barbosa, então diretoria do MAC, em São Paulo. Ver: Carta de Vilém Flusser a Ana Mae Barbosa, de 30 de outubro de 1990a. Inédito. Vilém Flusser Archive, Berlim. Outra menção a Derrida aparece em carta a Miguel Reale: "gente como Kitler, Bohringer, Baudrillard, Derrida (e eu próprio) procuram elaborar os critérios para orientarmo-nos em tal 'cultura imaterial', 'pós-histórica', 'informática', e sobretudo para captarmos o sentido de 'belo' depois da bancarrota dos valores ditos 'modernos'” (FLUSSER, 1991). Ver: Carta de Vilém Flusser a Miguel Reale, de 12 de fevereiro de 1991. Inédito. Vilém Flusser Archive, Berlim.
} 
passa por pensar o Brasil sem ser patriota. Por tomar distância do Brasil, mas sem perdê-lo de vista.

Embora nunca tenha assumido posições políticas propriamente radicais movimentos de resistência, filiação a partidos políticos ou a escritura de textos de caráter combativo - e tenha, nos anos 1960, aproximado-se de figuras conservadoras como Miguel Reale e José Bueno e excursionado pela Europa a convite do Itamaraty -, Flusser repudiava, desde sua condição desterrada e judia, toda forma de totalitarismo e se desencanta com a possibilidade de ver um país miserável recair em regime de exceção e desprezar suas potencialidades, que vinham, segundo ele, sobretudo da cultura. Flusser, nos anos 1970, com o país às voltas com uma ditadura e com os encerramentos dos espaços de pensamento, acredita que poderia refletir melhor sobre o lugar que lhe acolheu a partir da Europa. 0 engajamento de Flusser, com suas realizações e frustrações, pode indicar caminhos para pensar o Brasil.

\section{Referências}

DIDI-HUBERMAN, Georges. Cuando las imágenes toman posición. Tradução: Inés Bértolo. Madri: A. Machado, 2008.

FLUSSER, Vilém. Comunicologia: reflexões sobre o futuro: as conferências de Bochum. Tradução: Tereza Maria Souza de Castro. São Paulo: Martins Fontes, 2014.

FLUSSER, Vilém. Bodenlos: uma autobiografia filosófica. São Paulo: Annablume, 2007.

FLUSSER, Vilém. Em busca de significado. In: LUDUSANS, Stanislavs (org.). Rumos da filosofia atual no Brasil: em auto-retratos. Volume v. 1. São Paulo: Loyola, 1976, p. 495506.

FLUSSER, Vilém. [Correspondência]. Destinatário: Miguel Reale. São Paulo, 1 out. 1971. 1 carta. Inédito. Vilém Flusser Archive, Berlim.

FLUSSER, Vilém. [Correspondência]. Destinatário: Miguel Reale. Bochum, 12 fev. 1991. Inédito. Vilém Flusser Archive, Berlim.

FLUSSER, Vilém. [Correspondência]. Destinatário: Alan Meyer. Merano, 31 ago. 1973a. Inédito. Vilém Flusser Archive, Berlim.

FLUSSER, Vilém. [Correspondência]. Destinatário: José Bueno. Merano, 14 dez. 1973b. Inédito. Vilém Flusser Archive, Berlim. 
FLUSSER, Vilém. [Correspondência]. Destinatário: Dora Ferreira da Silva. Merano, 29 dez. 1975. Inédito. Vilém Flusser Archive, Berlim.

FLUSSER, Vilém. [Correspondência]. Destinatário: Edmar de Almeida. São Paulo, 5 dez. 1972. Inédito. Vilém Flusser Archive, Berlim

FLUSSER, Vilém. [Correspondência]. Destinatário: Roberto Gomes. Robion, 26 set. 1980. Inédito. Vilém Flusser Archive, Berlim.

FLUSSER, Vilém. [Correspondência]. Destinatário: José Bueno. Robion, 31 de ago. 1987a. Inédito. Vilém Flusser Archive, Berlim.

FLUSSER, Vilém. [Correspondência]. Destinatário: Maria Lília Leão. Robion, 5 maio 1987b. Inédito. Vilém Flusser Archive, Berlim.

FLUSSER, Vilém. [Correspondência]. Destinatário: Miguel Reale. Robion, 17 de jun. 1988. Inédito. Vilém Flusser Archive, Berlim.

FLUSSER, Vilém. [Correspondência]. Destinatário: Edgardo Pereira Mendes. Robion, 15 dez. 1978. Inédito. Vilém Flusser Archive, Berlim.

FLUSSER, Vilém. [Correspondência]. Destinatário: Ana Mae Barbosa. Robion, 30 out. 1990a. Inédito. Vilém Flusser Archive, Berlim.

FLUSSER, Vilém. [Correspondência]. Destinatário: Maria Lília Leão. Robion, 29 jan. 1990b. Inédito. Vilém Flusser Archive, Berlim.

FLUSSER, Vilém. [Correspondência]. Destinatário: Dora Ferreira da Silva. Robion, 29 jul. 1990c. Inédito. Vilém Flusser Archive, Berlim.

FLUSSER, Vilém. [Correspondência]. Destinatário: José Bueno. Robion, 9 maio 1990d. Inédito. Inédito. Vilém Flusser Archive, Berlim.

GOMES, Roberto. Crítica da razão tupiniquim. São Paulo: FTD, 1977.

HOLANDA, Sérgio Buarque de. Raízes do Brasil. 26 ed. São Paulo: Companhia das Letras, 1995.

MENDES, Edgardo P. [Correspondência]. Destinatário: Vilém Flusser. São Paulo, 23 jun. 1988. Inédito. Vilém Flusser Archive, Berlim.

SILVA, Dora Ferreira da. [Correspondência]. Destinatário: Vilém Flusser. São Paulo, 10 jun. 1973a. Inédito. Vilém Flusser Archive, Berlim.

SILVA, Dora Ferreira da. [Correspondência]. Destinatário: Vilém Flusser. São Paulo, 5 maio 1973b. Inédito. Vilém Flusser Archive, Berlim.

VARGAS, Milton. [Correspondência]. Destinatário: Vilém Flusser. São Paulo, 21 nov. 1990. Vilém Flusser Archive, Berlim. 


\title{
Groundless engajament: Vilém Flusser's relationship with Brazil
}

\begin{abstract}
Vilém Flusser is an uprooted thinker. Jewish and prague, has the family murdered by the Nazis. After a year in England, arrives in Brazil in 1940, where he would live for just over three decades. Multilingual philosopher, makes self-translation his presupposition of thought, postulating that there are as many realities as the articulated languages. He returned to Europe in 1972 and, since then, lives between lectures and conferences, without formally affiliating himself with any academic institution. Despite his groundless biography and philosophy, the concept of engagement was still central to his work, especially for the time he lived in Brazil. It is in Brazil that the affective and political placement of a place crosses the thinking of this stateless philosopher, a feeling that accompanies him until the end of his life. The purpose of this article, based on a careful reading of the unpublished correspondences with some of its main interlocutors, is to discuss Flusser's Brazilian engagement. The premise is that Flusser forged an imaginative model, albeit without the claim to formulate a "Brazilian philosophy", which can serve as a critical key for understanding contemporary Brazil. The doubts about the forms of engagement in Brazil, which crossed Flusser's life, especially in the 1970s, are brought to the table again.
\end{abstract}

\section{Keywords}

Vilém Flusser. Brazil. Europe. Engajament. Correspondences.

Recebido em 30/05/2020

Aceito em 28/08/2020 